\title{
Chinese WeChat Users and Their Behavioural Features: A Case Study Based on the Grounded Theory
}

\author{
Yanyu Wang \\ Yango University \\ Xiao Huang \\ Yango University \\ Camilla Wang \\ (Corresponding Author) \\ Shantou University
}

WeChat is a social medium for mobile phones developed by the Chinese company Tencent in 2011. By March 2018, there were one billion active WeChat users, making it the social software with the fastest development in China. Most Chinese WeChat users share WeChat Moments, establish WeChat groups, send WeChat red envelopes, and become WeChat Businessman on WeChat. This paper probes the features of WeChat user behavior in light of the Grounded Theory. The findings revealed four behavioral features: the expression of personality, the connection between individuals, group establishment by individuals, and the connection between individual and group. From the perspective of interpretivism, this paper analyzed such behavior and found that WeChat users are individuals with different characters. Sharing WeChat Moments enables users to become unique individuals and express their personalities in certain social circles. In addition, people through WeChat Moments and WeChat red envelopes enhance the connections among individuals. WeChat Businessman also develops via the connection between individuals. Different individuals can form WeChat groups according to other contexts, and individuals in different groups can have something in common. The connection between individual and group is also a social need. The virtual world established in WeChat can be called the "WeChat world."

Keywords: interpretivism, red envelope, WeChat group, WeChat moments, WeChat store

\section{INTRODUCTION}

In 2011, the Chinese company Tencent launched WeChat, a social medium for mobile phones they had developed for several years. The number of WeChat users has soared since its launch. By March 2018, there were one billion active users monthly (Ma, 2018). WeChat attracted many users so quickly that nearly all the functions based on computers or mobile phones are integrated into the app. With WeChat, users can share their life experiences, thoughts, and photos on WeChat Moments and join or establish different social groups to have real-time interaction with friends on WeChat Moments or WeChat groups. Moreover, users 
can virtually send WeChat red envelopes (electronica transfer money from one person to others as gifts) and engage in WeChat business transactions.

As WeChat has developed so rapidly, increasing research has been done on WeChat in China. The existing studies on WeChat focus on WeChat as software, the social influence of WeChat, the relationship between WeChat and communication, and the connection between WeChat and traditional media (Liu \& Hsu, 2014). Some researchers have explored WeChat from a philosophical perspective. For instance, Xiaoming Chiang probed into the WeChat culture from a philosophical angle (Chiang, 2017). Sun Wei studied WeChat technology from the standpoint of existential phenomenology (Sun, 2015). Li researched public opinions on WeChat from the angle of philosophical hermeneutics (Lee, 2015). Many studies have been conducted on WeChat as software, the relationship between WeChat and sociology, and WeChat and communication.

However, the studies probing into the use of WeChat from a philosophical perspective are relatively limited. This paper explores WeChat from a philosophical angle. Based on the Grounded Theory, this paper examines WeChat user behavior by looking at the following four behavioral features: the expression of personality, the connection between individuals, group establishment by individuals, and the connection between individual and group. By studying the behavior of Wechat users in China, the paper conducts further research on the characteristics of Chinese social behavior and consumer behavior. It offers suggestions for enterprises to develop new products, provide new services, and strengthen communication with consumers.

\section{MAIN WECHAT USER BEHAVIOUR IN CHINA}

WeChat has many functions; however, Chinese users most frequently accessed WeChat Moments, WeChat Group, WeChat Red Envelope, and WeChat Store.

\section{WeChat Moments}

WeChat moments refers to a social function on Tencent Wechat. Users can post text and pictures on "Moments" and share articles or music from other applications. Users can "praise" or "comment" on new photos of their friends, while other users can only see "praise" or "comment" from the same friends. This function enables users to share, display, and show what they have (Liang, 2008). They share their experiences and thoughts in daily life in the form of words, photos, or video clips (Wang and Kuan, 2016). It is best to show the We Media function of WeChat (Lee, 2014). Before releasing information, WeChat users can decide on the WeChat friends who can see the information through the app's permission settings. In 2014, Huan Wang and Jing-wen Guan surveyed college students at two universities in Beijing and found that $76 \%$ of them shared their life experiences on WeChat Moments and that only a few would share something else.

Moreover, different ages vary in what is shared, and female users are more active sharers than male ones (Wang \& Guang, 2016). After a user shares something on WeChat Moments, his/her WeChat friends can interact with him or her by pressing "Like" and making comments. "Like" is set as a thumbs-up sign, meaning: what shared has been read, what shared is agreed, and is highly appreciated. "Comments" refers to the comments on what is being shared. The familiar WeChat friends of the user can only mutually see likes and comments, and knowledgeable friends can make mutual comments.

\section{WeChat Group}

One of the primary WeChat user behavior is to join and form WeChat groups. This function enables users to locate different groups. WeChat groups can be established by work, life, study, and kinship. Different kinds of WeChat groups can meet different needs. For example, a WeChat group based on life is designed for fun and relaxation, and one based on friendship offers a social sense and a sense of fulfillment featuring self-improvement (Wang \& Chu, 2014).

In China, WeChat users tend to communicate with each other to solve unexpected public events. After analysis, Yu-lin Chao pointed out that the general circumstances on WeChat in China arise from the 
intention to safeguard or seek immediate interests. For instance, the community residents might form a WeChat group to oppose illegal buildings in the neighborhood, or parents might form a WeChat group to discuss the health or study of their children. These groups are established and joined by direct interested parties and are designed to solve group problems. With WeChat Group, they can quickly share information and protect their rights and interests. In addition, they can evade taking responsibility for their actions because they are engaging in collective participation, and the participation is based on a close relationship (Chao, 2018).

\section{WeChat Red Envelope}

In 2014, WeChat launched the Red Envelope function. In Chinese culture, "red envelope" refers to the gift money for children during the Spring Festival. As red is an auspicious color in China, the gift money is usually wrapped in red paper or red paper bags. This is how "red envelope" got its name. Today, "red envelope" is not confined to the gift money for children; it also refers to the gift money for others on a joyful event. Featuring easy operation and intense interaction, it has attracted high user viscosity (Chang, 2016). It is a kind of convenient payment, and there had been various methods to make payment before it came into being. Nevertheless, WeChat Red Envelope has many unprecedented functions. It supports oneto-one payments, one-to-group payments, and group-to-group payments.

In addition, the amount can be randomly set in cases of one-to-many payments and many-to-many payments. A red envelope indicates joy and luck; hence, this function quickly prevailed in China. In many WeChat groups, snatching red envelopes has become a phenomenon. A user sends red envelopes (the individual users will determine each envelope and number of envelopes sent out) in a WeChat group. Then other users can snatch one with a different amount according to their speed. In this way, a small amount of money can activate the whole WeChat group. Some users have adopted it as an effective way to release information that requires attention. As is shown in the studies by Peng Lan and other researchers, the top three reasons for users to use WeChat Red Envelope are "to achieve a low-cost social connection," "to be accepted in a group more effectively," and "to enjoy the random competition in the snatching of red envelopes" (Peng, 2017).

Apart from individuals, the media has adopted WeChat Red Envelope for marketing as well. In 2014, WeChat Red Envelope attracted over eight million WeChat users within nine days during the Chinese Spring Festival, and more than 40 million red envelopes were received (Tencent, 2015). On February 22, 2018, WeChat released an official report on WeChat statistics during the Spring Festival in 2018. That year, 768 million people conveyed their New Year blessing through WeChat Red Envelope (TechWeb, 2018). Using WeChat Red Envelope for payment and advertising will become increasingly popular among both individuals and media.

\section{WeChat Store}

WeChat Store appeared in 2013, and Taoyong Sun, the CEO of Weimob, was the first to propose the concept. According to him, WeChat Businessman has two layers of meaning. First, it refers to a WeChat businessperson who uses a WeChat account for marketing that involves a connection between businesses and consumers. Second, it indicates a self-employed businessperson who opens a store on WeChat Moments and directly contacts consumers in individual-to-individual marketing (Sun, 2014). In this paper, WeChat Businessman referred to a self-employed businessperson who opens and does marketing on WeChat Moments. From 2014 to 2016, the volume of the market transactions by Chinese WeChat businesspeople rose from RMB95.03 billion to RMB360.73 billion, with an annual growth rate of 93.5\%. The number of WeChat businesspeople rose from 10,241,000 in 2014 to $12,574,000$ in 2015 and to $15,352,000$ in 2016 (Hsu, 2018).

According to the survey by Lixia Wang and Yuchi Shih, the commodities most frequently advertised on WeChat Moments are cosmetics and skincare products, accounting for $80.95 \%$, followed by clothes and shoes (53.74\%), weight loss products, healthcare products, and snacks (about 20\%), daily necessities and ornaments (about 11\%), and luxury goods (6.12\%) (Wang \& Shih, 2018). According to some researchers, cosmetics and skincare products, which take the most significant proportion, are sold based on a relatively 
close interpersonal relationship. For example, Shaohua Li and other researchers stated that WeChat is a platform featuring a solid social connection and that WeChat business is conducted based on a reliable connection. By spreading and sharing information about recommended goods in a circle with a strong social bond, WeChat businesspeople deepen the public understanding of their products and arouse their trust to increase sales volume (Lee \& Yang, 2015).

\section{GROUNDED THEORY-BASED SUMMARY OF CHINESE WECHAT USER BEHAVIOR}

As WeChat is a new social medium in China, Chinese WeChat users show particular user behavior. The behavior mentioned above, such as sharing WeChat Moments, establishing WeChat groups, snatching WeChat red envelopes, and doing WeChat business, are the primary WeChat user behavior. This paper investigated if such behavior could reflect any behavioral features of Chinese WeChat users. The authors adopted the Grounded Theory to probe these behavioral features.

In this study, we selected 11 people as informants for an in-depth interview. As the Grounded Theory requires that the samples be representative, we chose consumers who used different WeChat functions. All these WeChat users spent over three hours on WeChat per day, and the functions they frequently used were WeChat Moments, WeChat Group, WeChat Red Envelope, and WeChat Store. Table 1 contains the basic information of the interviewees.

TABLE 1

PROFILE OF INTERVIEWEES

\begin{tabular}{|c|c|c|c|c|c|c|c|}
\hline NO. & Name & Gender & Age & Career & $\begin{array}{l}\text { Year of } \\
\text { first } \\
\text { use }\end{array}$ & $\begin{array}{l}\text { Daily time (in } \\
\text { hours) spent on } \\
\text { WeChat }\end{array}$ & $\begin{array}{l}\text { Frequently-used } \\
\text { WeChat Functions }\end{array}$ \\
\hline 1 & Lin $X X$ & Female & 42 & $\begin{array}{l}\text { WeChat } \\
\text { businessman of } \\
\text { tea leaf }\end{array}$ & 2011 & 5 & $\begin{array}{l}\text { Advertise and } \\
\text { marketize tea leaves }\end{array}$ \\
\hline 2 & Hua XX & Male & 46 & $\begin{array}{l}\text { Company } \\
\text { employee }\end{array}$ & 2013 & 3 & $\begin{array}{l}\text { Communicate with } \\
\text { clients }\end{array}$ \\
\hline 3 & Lin $X X$ & Female & 41 & $\begin{array}{l}\text { Company } \\
\text { supervisor }\end{array}$ & 2011 & 4 & $\begin{array}{l}\text { Issue notices in the } \\
\text { workgroup and } \\
\text { answer questions } \\
\text { raised by employees }\end{array}$ \\
\hline 4 & $\begin{array}{l}\text { Liang } \\
\text { XX }\end{array}$ & Female & 21 & College student & 2014 & 5 & $\begin{array}{l}\text { Share different } \\
\text { things on WeChat } \\
\text { Moments }\end{array}$ \\
\hline 5 & Lin $X X$ & Female & 35 & $\begin{array}{l}\text { Cashier of a } \\
\text { drugstore }\end{array}$ & 2011 & 5 & $\begin{array}{l}\text { Share something } \\
\text { about the user and } \\
\text { his/her child on } \\
\text { WeChat Moments }\end{array}$ \\
\hline 6 & $\begin{array}{l}\text { Chang } \\
\text { XX }\end{array}$ & Male & 41 & College teacher & 2011 & 3 & Make confirmations \\
\hline 7 & $\begin{array}{l}\text { Yuan } \\
\text { XX }\end{array}$ & Female & 19 & College student & 2016 & 6 & $\begin{array}{l}\text { Share selfies on } \\
\text { WeChat Moments }\end{array}$ \\
\hline 8 & $\begin{array}{l}\text { Fang } \\
\mathrm{XX}\end{array}$ & Female & 42 & $\begin{array}{l}\text { Company } \\
\text { employee }\end{array}$ & 2014 & 5 & $\begin{array}{l}\text { Publish } \\
\text { advertisements }\end{array}$ \\
\hline 9 & $\begin{array}{l}\text { Chen } \\
\text { XX }\end{array}$ & Male & 22 & College student & 2015 & 5 & $\begin{array}{l}\text { Read news about } \\
\text { friends and chat } \\
\text { with them }\end{array}$ \\
\hline
\end{tabular}




\begin{tabular}{|l|l|l|l|l|l|l|l|}
\hline 10 & Kao XX & Male & 24 & College student & 2013 & 6 & $\begin{array}{l}\text { Read various } \\
\text { WeChat push } \\
\text { notifications }\end{array}$ \\
\hline 11 & $\begin{array}{l}\text { Wang } \\
\text { XX }\end{array}$ & Male & 65 & Retiree & 2015 & 3 & $\begin{array}{l}\text { Communicate with } \\
\text { children and send } \\
\text { WeChat red } \\
\text { envelopes }\end{array}$ \\
\hline
\end{tabular}

Source: Compiled by the author according to the information from the interviewees

In this study, the one-to-one in-depth interview method was utilized to collect first-hand data about the interviewees. An appointment was made with each interviewee in advance; the interview was made according to the interview plan. During the interview, additional questions were asked according to the answers, and the interviewees were encouraged to give specific examples. Each interview lasted for about an hour, and the records of WeChat use were read, photographed, and stored with the users' permission.

The interviews and WeChat use records were transcribed, and the interviewees confirmed the scripts. As for incomplete information, the interviewees were asked to offer more details for completion. Finally, the collected data were analyzed, and other data were used for the theoretical saturation test. All the collected data were analysed and summarized in this study, and any invalid information or scripts with little details were eliminated. The valid were used for open coding and were tagged. In the process, 23 ideas were generated (see Table 2).

TABLE 2 SUMMARY OF INTERVIEWS AND INTERVIEWEES' THOUGHTS

\begin{tabular}{|l|l|}
\hline \multicolumn{1}{|c|}{ Interview Record Examples } & \multicolumn{1}{|c|}{ Thoughts } \\
\hline $\begin{array}{l}\text { I often share something about traveling and food on WeChat } \\
\text { Moments. Sometimes, I have the urge to do so even after } \\
\text { taking a picture of a beautiful flower. That's because I want to } \\
\text { share something extraordinary with my friends. I will feel } \\
\text { pleased if my friends like or comment on what I share. }\end{array}$ & \\
\hline $\begin{array}{l}\text { Most of what I share on WeChat Moments is about my child. } \\
\text { I want to take photos of my lovely child and share them on }\end{array}$ & \\
WeChat Moments. I do it for two reasons. First, I want to \\
record everything about the personal growth of my child. \\
Second, I will have a sense of achievement if my friends like \\
what I share. \\
\hline $\begin{array}{l}\text { I don't like sharing something on WeChat Moments, and I will } \\
\text { just do it on several occasions for a whole year. However, I }\end{array}$ \\
$\begin{array}{l}\text { will read what my friends share every day because I want to } \\
\text { know what happens in their daily life and clicking "like" on } \\
\text { what is shared by my close friends will deepen our friendship. }\end{array}$ \\
\hline $\begin{array}{l}\text { My parents are very strict with me, so I don't talk too much } \\
\text { with them at home. I've dreamed of becoming a singer since } \\
\text { childhood. But I've never been brave enough to talk about it } \\
\text { with them because they would oppose it. I look more attractive } \\
\text { in photos, especially in those modified ones. Whenever I share } \\
\text { my photos on WeChat Moments, all my friends will be } \\
\text { amazed. I'm not a singer, but I have gained much confidence } \\
\text { on WeChat Moments. }\end{array}$ \\
\hline
\end{tabular}




\begin{tabular}{|c|c|}
\hline $\begin{array}{l}\text { I think some people have mistaken themselves as stars by } \\
\text { sharing too many details about their lives, such as having } \\
\text { dinner, buying clothes, and running. I used to read all that was } \\
\text { shared, but later I found that it is a waste of time. Now, I only } \\
\text { follow some close colleagues and friends. }\end{array}$ & $\begin{array}{l}\text { It creates star effects in the social } \\
\text { circle. }\end{array}$ \\
\hline $\begin{array}{l}\text { WeChat Moment is an extraordinary place where I can say } \\
\text { something hard to say in the physical world. On one occasion, } \\
\text { our team worked overtime, and we were all swamped. I caught } \\
\text { a cold. But as it was not so severe, I didn't ask for leave. I went } \\
\text { to see a doctor in a small clinic before working, where I got } \\
\text { some medicine and received a nebulization treatment. I took a } \\
\text { selfie and shared it on WeChat Moments. All my colleagues } \\
\text { showed their concerns when I arrived at the workplace. }\end{array}$ & $\begin{array}{l}\text { It is a particular channel to express my } \\
\text { mind. }\end{array}$ \\
\hline $\begin{array}{l}\text { I don't like sharing anything on WeChat Moments and seldom } \\
\text { do so throughout the year. However, I will read what my } \\
\text { friends share because I want to know what happens in their } \\
\text { daily life, and clicking "like" for what is shared by my close } \\
\text { friends will deepen our friendship. }\end{array}$ & $\begin{array}{l}\text { It is a channel for me to get news about } \\
\text { my friends. }\end{array}$ \\
\hline $\begin{array}{l}\text { What fascinates me the most about WeChat are the classmate } \\
\text { groups, through which I can get in touch with classmates I } \\
\text { haven't seen for years. In the classmate groups, we talk about } \\
\text { our childhood, which gives us a sense of nostalgia. }\end{array}$ & It meets the need to contact classmates. \\
\hline $\begin{array}{l}\text { I'm a department supervisor, and there is a WeChat workgroup } \\
\text { where our department members can get notices and } \\
\text { communicate with each other. I can send all notifications to } \\
\text { the group, which has made my work much more efficient. }\end{array}$ & $\begin{array}{l}\text { It meets my work needs in the } \\
\text { company. }\end{array}$ \\
\hline $\begin{array}{l}\text { As a salesman, I need to communicate with clients and answer } \\
\text { their questions. With WeChat, I can share with clients } \\
\text { regularly. It's very convenient. In the past, I could talk with } \\
\text { only one client through a phone call. But now, I can } \\
\text { communicate with several clients at the same time. It's } \\
\text { efficient. Besides, all problems can be discussed, and the } \\
\text { frequency of communication with clients has significantly } \\
\text { higher. }\end{array}$ & $\begin{array}{l}\text { It meets mine needs to communicate } \\
\text { with clients. }\end{array}$ \\
\hline $\begin{array}{l}\text { Of all my WeChat groups, my favorite one is the photographer } \\
\text { group. In this group, we often share the knowledge and skills } \\
\text { of photography. We also go to take pictures together regularly. } \\
\text { All my questions will be immediately answered in the group. } \\
\text { Moreover, I frequently take photos outdoors with them. }\end{array}$ & $\begin{array}{l}\text { It meets my needs to develop my } \\
\text { hobbies. }\end{array}$ \\
\hline $\begin{array}{l}\text { I've joined many WeChat groups, but I seldom say anything in } \\
\text { them because it is a waste of time to do so. However, I will } \\
\text { check some main workgroups or liaison groups several times } \\
\text { every day for important notices. }\end{array}$ & It meets my needs to check my work. \\
\hline $\begin{array}{l}\text { Aside from some permanent WeChat groups, I have some } \\
\text { temporary ones. For instance, we established a quick group for } \\
\text { traveling, through which we got notices and communicated } \\
\text { with each other. The group was eliminated right after the trip. } \\
\text { Temporary groups are convenient. }\end{array}$ & $\begin{array}{l}\text { It meets our needs for temporary } \\
\text { communication. }\end{array}$ \\
\hline $\begin{array}{l}\text { I have retired. My children are busy with their work and } \\
\text { seldom come back home or give me a phone call. So, it is hard }\end{array}$ & $\begin{array}{l}\text { It meets the need to communicate with } \\
\text { family members. }\end{array}$ \\
\hline
\end{tabular}


for me to know their situation. Now, I've formed a WeChat family group, where I often ask something about their lives, and they will respond whenever they are free. I established this group to tell them that we always miss them.

Since the WeChat Red Envelope launch, we often snatch red envelopes in our WeChat group for middle school classmates. It's fascinating. The amount in some red envelopes is small, and sometimes it is only RMB0.01. But we all find it interesting and exciting.

In the past, elderly family members used to give gift money during the Spring Festival. Now we have a WeChat family group where we often send red envelopes. It saves us time. But our grandparents don't know how to operate WeChat and thus fail to send red envelopes. WeChat Red Envelope is very convenient, but the sense of ritual in the traditional conduct of sending gift money in red envelopes has been diminished.

As a WeChat businessman, I've joined many WeChat groups for marketing, but many of these groups are not active. Sometimes, I send red envelopes to advertise my products, and the red envelopes will be snatched quickly. Then, I can promote my products. By doing so, they will pay attention to my advertisement.

When WeChat Red Envelope started, my children taught me how to operate it, and I found it very interesting. I used to send red envelopes in the WeChat groups, but I don't do that now because my children focus on snatching red envelopes back at home and don't talk to me.

Since the launch of WeChat Red Envelope and WeChat Transfer, my friends and I have shared the cost whenever we have dinner or buy things together. It's convenient. In the past, people competed to pay the bills of parties, and sometimes it would be hard for me to pay if I didn't have any change. I felt tremendous pressure when others paid the bills for me. But now it is a different situation. I can give any amount of money to those who pay bills through WeChat, and I don't feel pressure to attend any party now.

As a WeChat businessman, I put on advertisements and answer customer questions in WeChat groups every day. I focus on old customers, and the sales volume is satisfying. But sometimes I'm afraid that my advertisements may cause disgust from my friends.

I have a job and never thought of becoming a WeChat businessman. But my sister-in-law always encouraged me to join her. As the advertisement pictures all come from her, all I need to do is to forward them. It's very convenient. If there is an order, I will send the order to her. It doesn't take much time, so I do it.

Many of my friends are WeChat businesspeople. If some of their products attract me, I will buy some from them. As we
It meets the need to activate our social atmosphere.

It is a place where red envelopes are sent and snatched up among family members.

It helps me grab the attention of WeChat group members.

It reduces the physical communication among family members.

It has changed our social connection.

I can work as a WeChat

businessperson.

I can work as a part-time WeChat

businessperson.

I can buy things from friends who are

WeChat businesspeople. 
are familiar with each other, I don't think they will cheat me, and I believe that the products they recommend will be good. I am a WeChat businessman, and I think I'm a highly I sell products to friends through conscientious one. All the products I sell are legal and genuine. WeChat Businessman. I often communicate with my friends and know what they need to recommend products that are suitable for them. And they show great trust in me.

Source: Compiled by the author according to data collected from the interviews.

In this study, 23 ideas were generated through the open coding mentioned above. These 23 relatively separated views were analyzed and connected to form four categories and two main categories. The four categories were the expression of personality, the connection between individuals, group establishment by individuals, and the connection between individual and group. One main category was induced from these four categories (see Table 3).

TABLE 3

SUMMARY OF THE MAIN CATEGORY, CONCEPTS, AND CORRESPONDING IDEAS

\begin{tabular}{|c|c|c|}
\hline Main Category & Category & Corresponding Idea \\
\hline \multirow{4}{*}{$\begin{array}{l}\text { An individual- } \\
\text { oriented interactive } \\
\text { social connection }\end{array}$} & $\begin{array}{l}\text { The expression } \\
\text { of personality }\end{array}$ & $\begin{array}{l}\text { "It's a platform to show my child." } \\
\text { "It helps me become the main figure in my life." } \\
\text { "It creates star effects in the social circle." } \\
\text { "It is a special channel to express my mind." }\end{array}$ \\
\hline & $\begin{array}{l}\text { The } \\
\text { connection } \\
\text { between } \\
\text { individuals }\end{array}$ & $\begin{array}{l}\text { "It is a channel for me to get news about my friends." } \\
\text { "It's a channel to interact with my friends." } \\
\text { "It meets my needs to communicate with clients." } \\
\text { "I can buy things from friends who are WeChat businesspeople." } \\
\text { "I can work as a WeChat businessman." }\end{array}$ \\
\hline & $\begin{array}{l}\text { Group } \\
\text { establishment } \\
\text { by individuals }\end{array}$ & $\begin{array}{l}\text { "It meets our needs to contact classmates." } \\
\text { "It meets my needs to develop my hobbies." } \\
\text { "It meets my work needs in the company." } \\
\text { "It meets our needs for temporary communication." } \\
\text { "It meets our needs to communicate with family members." } \\
\text { "I can work as a WeChat businessman." }\end{array}$ \\
\hline & $\begin{array}{l}\text { The } \\
\text { connection } \\
\text { between } \\
\text { individual and } \\
\text { group }\end{array}$ & $\begin{array}{l}\text { "It's a platform where I share something with my friends." } \\
\text { "It meets my needs to check work." } \\
\text { "It meets our needs to activate our social atmosphere." } \\
\text { "It is a place where red envelopes are sent and snatched up } \\
\text { among family members." } \\
\text { "It has changed our social connection." } \\
\text { "It helps me grab the attention of WeChat group members." } \\
\text { "It reduces the physical communication among family } \\
\text { members." }\end{array}$ \\
\hline
\end{tabular}

Source: Compiled by the author according to data collected from the interviews.

According to the above summarization, Chinese WeChat users show four behavioral features: the expression of personality, the connection between individuals, group establishment by individuals, and the connection between individual and group. These four behavioral features could be summarized as individual-oriented interactive social connections. Each user exists as a different and unique individual, but an individual can't live alone. In society, each individual shows some social behavior. The primary social 
connections of each individual include an individual's relationships with others, groups of different individuals that form according to different contexts, and the relationship between individual and group.

\section{INTERPRETIVISM-BASED ANALYSIS OF CHINESE WECHAT USER BEHAVIOR}

The social, behavioral features of WeChat users could be analysed from the perspective of interpretivism. Derived from hermeneutics, Social Constructivism, Phenomenology, Ethnography, Semiology, Humanism, and other philosophical ideas and research methods, interpretivism has evolved into an independent philosophical idea. The main concepts of interpretivism include the following points (Chu, 2007; ):

1) It recognizes and respects the existence of individuals.

2) Truth and meaning cannot be generated without a situation or context.

3) Truth or meaning is generated in the interaction between "persons" or "humans and society."

4) There is no objective world because human beings established the so-called world, and the world is projected from human ideas.

5) The understanding of things is always a recycling process, and this process is called a cycle of interpretivism. The relationship between wholeness and individual parts is one featuring cycle and unfolding. Individuals first get to know the details and then understand the whole through the facts, and vice versa (Inagaki, 2013).

In the following section, emphasis is placed on how the philosophical ideas of interpretivism are shown in the social, behavioral features of WeChat users.

\section{Recognition of and Respect to Individuals}

The fundamental idea of interpretivism is to recognize and respect the existence of individuals. With WeChat Moments, each user can become a star in certain social domains through easy operations to share photos, behavior, and thoughts. According to Jin-feng Yin, WeChat Moments is a stage where users can show rituals to their friends. By shaping their self-image with words, pictures, and facial expressions, they have an opportunity to catch the attention of friends (Yin \& Hu, 2018). According to Lingning Wang and Juan Lan, Chinese consumers, especially young people, express their self-consciousness and personality on WeChat Moments. In people's faces other than the target audience, their discourse is self-centered (Wang \& Lan, 2017).

Although ordinary users can release information on blogs, Sina Microblog, and other social media, it is rather difficult to attract people and maintain continual attention. At present, famous bloggers are either stars or those with unique talents, and it is hard for most people to become a star in Sina Microblog. Nevertheless, it is a different story when WeChat is concerned. Ordinary users can receive attention and become a star or central figure by merely sharing some photos or articles. It is safe to say that WeChat has provided everyday users with an excellent stage to show themselves. Each individual is unique on WeChat Moments, and such existence can be revealed and recognized on WeChat Moments.

\section{The Connection Between Individuals}

According to interpretivism, truth or meaning is generated in interpersonal interaction. It takes time and energy to maintain a friendship. Compared with the exchange in real life, online interaction is more straightforward. Many WeChat functions are designed to facilitate interaction. For instance, a user can interact with his/her friends by clicking "like" or commenting on what they share on WeChat Moments. Such interaction is so convenient that users are more ready to participate. Some users may not click on "like" or make comments, but they can still keep themselves abreast of the life experiences of their friends and then talk about the experiences if necessary. This helps enhance friendship and is also a kind of interaction.

If a salesperson can use WeChat to communicate with several clients simultaneously, the frequency of communication will become high, and his/her work will become more efficient. The relationship between a WeChat businessperson and a client can become one between a seller and a buyer due to the frequent 
interaction between them. A WeChat businessperson can evaluate the preference of his/her friends and make timely interactions with them, thus achieving targeted marketing. If a WeChat businessperson has a closer relationship and interacts more frequently with WeChat users, his/her advertisement will be mainly accepted (Mao \& Chi, 2017). It is safe to say that various Chinese WeChat user behaviors facilitate the interaction between individuals and maintain a close relationship through such exchanges. Moreover, a new value will be created in the interaction. For example, WeChat Businessman is a new marketing model that arose from the interactions among users.

\section{Group Establishment by Individuals: Situation and Context}

According to interpretivism, the world is projected by human beings, and truth or meaning will not be generated without a situation or context. People with different cultures, experiences, or backgrounds will see the world in different ways. However, for those who share the same culture, experience, or environment (all these can be called the "situation" or "context"), the world they establish will be the same and will have a specific meaning. Take the example of a WeChat class group of middle school students. The group will be formed on the basis that the users spend their middle school days together. A WeChat workgroup in a company will be founded on the workplace and the work relations shared by the employees. A WeChat photography group will be built based on the group members' shared passion for photography. In certain WeChat groups, group members share a concept that serves as the foundation of a world where they are intelligible to each other.

Humans have different forms of existence according to other reference systems. In general, humans exist in a category, in a group, and as individuals. The WeChat culture is a miniature of these three forms of existence. Meanwhile, these three forms of existence are integrated into the WeChat culture (Chiang, 2017). Humans are creatures that live in groups and cannot live without society. To survive, individuals must relate themselves to social groups, which are bound by specific ties. Individuals will lose the meaning of living if they are separated from a group. Individuals live in different scales and type groups, and such groups can be international, regional, national, or familial. Groups can also be related to career, age, gender, and a common interest (Chiang, 2017).

WeChat social groups enable people to form different groups according to different contexts quickly. These groups have various forms. Some groups are regular and long-term ones that feature frequent interaction, such as workgroups and family groups. Some groups are established for occasional exchange, including class groups and friend groups. Other groups are temporary ones designed for specific missions. Whatever kind of WeChat group, there is a high degree of freedom to form a group, interact and dismiss.

\section{The Connection Between Individual and Group: The Human-Group Interaction}

According to interpretivism, truth and meaning are generated in human-society interaction. WeChat groups also need interaction, and a WeChat group without expression or dialogue would be meaningless. However, WeChat groups are not like society, where a group will be immediately dismissed if there is no dialogue or communication in it. A WeChat group can stay in a virtual form. Even if it keeps silent for a long time, it will become active when it is needed. WeChat Red Envelope is an excellent tool to active a WeChat group, and it is a unique form of interaction on WeChat. Compared with verbal expression, red envelope-based presentation features less risk.

Moreover, its auspicious symbolic meaning in Chinese culture also makes it quickly accepted in all situations. The red envelope-based payment system has also changed social payment methods among Chinese groups. As mentioned above, the function enables Chinese people to shift from the traditional "bill payment by one" to sharing the cost, allowing people to feel more relaxed about participating in social group activities. As many work teams have formed a WeChat workgroup, users must check their groups to get the latest information or communicate with others. It is safe to say that WeChat has changed how individuals and groups are connected and how the relationship is maintained. For instance, a group that would be immediately dismissed because of zero communication, in reality, can strengthen the relationship between individuals and the group. Moreover, WeChat Red Envelope has made the individual-group 
relationship more active and even changed the traditional Chinese social connections in a group of people, thus allowing some users to participate in social activities with more ease.

\section{FINDINGS AND DISCUSSION}

\section{Individual-Oriented Interactive Social Connection}

The findings of this study indicate that the Chinese WeChat user behavior can be summarized as "individual-oriented social connection," and WeChat has made such a social connection possible. The virtual world established on WeChat can be called the "WeChat world." As the WeChat world offers many conveniences, it is easy for WeChat users to indulge in it. According to statistics, over $20 \%$ of Chinese Internet users check their mobile phone 100 times a day; 23\% would feel panic without their mobile phone, and 34\% would check WeChat right after getting up in the morning (Iydnews, 2014).

As WeChat functions advance, the WeChat world will become better. In this world, users can lead a basic life as individuals. For instance, they can access various services, such as ordering food, shopping, paying bills, and calling a cab. They can also make friends with others and interact with friends at any time and in any place. Much information about work can be obtained and processed in time through WeChat groups. In addition, individuals can collect data from various channels, including news and popular articles. The WeChat world can meet social needs. For some users, the WeChat world can nearly replace the physical world. Nevertheless, there are many problems in an individual-oriented social connection, such as false impressions of individuals and false beliefs of interactions.

\section{False Impressions of Individuals}

Some WeChat users are passionate about sharing every detail about their life on WeChat Moments, no matter the significance. What they share can be a photo or a thought. According to Chienkuo Chiang, individuals strive to show their lives and seize all opportunities to do so. Insignificant daily experiences can be something they share on WeChat Moments (Chiang, 2014). Such users regard themselves as the center of WeChat Moments and often want to attract public attention there. What is shared on WeChat Moments also contributes to the shaping of their self-image. Some technologies, such as Photoshop and Beauty Camera, can facilitate the shaping and create intended effects to highlight themes. These technologies make it hard for other WeChat users to know the actual image of the users, and even the users themselves may indulge in the false impression.

In addition, WeChat can be as valuable as a dictionary, a book, a teacher, or an older fellow. As an individual, a user can have easy access to much knowledge and information according to his/her needs and hobbies, thus acquiring knowledge according to personal demands. However, too much information will distract one's attention. As a result, individuals might not have enough time or energy to digest what WeChat offers. They might scan and forward what is shown rather than deliberating or evaluating it (Wang, 2016).

The closed structure of WeChat Moments allows little space for external information, and the selfcorrection of data in time and space cannot be achieved. Therefore, the mobile environment and the fragmented time for the use of WeChat make it difficult for users to engage in in-depth reading. Such shallow, fast, and utility-oriented reading can lead to shallow thinking featuring unconditional acceptance of information (Wang, 2014). Such individual-oriented learning and reading on WeChat are false impressions and are not as effective as in the physical world.

\section{False Impressions of Interactions}

Some users have many WeChat friends and interact with these friends frequently every day. As a result, they mistakenly believe that they have many friends. According to Chienkuo Chiang, the friend circle, which is connected via WeChat accounts, does not consist of friends in the traditional sense but rather as acquaintances in the social mind. It is not a small social circle that is built upon trust. Therefore, there is a significant difference between the WeChat friend circle and a physical, social circle. WeChat-based communication is a kind of restricted and fragmented communication, which lacks complete-textual 
meaning. The fragmented society established online is loose (Chiang, 2014). The communication on WeChat is done without the physical presence of both parties; therefore, it is not affectionate interaction in an absolute sense.

Those adopting WeChat communication may become involved in the virtual world and pay no attention to the physical world, resulting in a gap between fantasy and reality or an understanding of misplacement. A high frequency of such absent communication may lower the frequency of face-to-face communication. The social connection may have been widened, but the intimacy has been diminished (Chiang, 2017).

In a physical society, older family members play a leading role in sending gift money in red envelopes during the Spring Festival. They regard it as an excellent chance to show their authority in the family. However, WeChat Red Envelope has taken away the leading role from elder family members who cannot send WeChat red envelopes. As a result, they retreat to a secondary position and are even separated from the ritual. Therefore, the impacts of WeChat Red Envelope on Chinese familial relationships may include shaking the traditional vertical axis-centered family structure, eliminating the boundary between family and social connections, and destroying the sacred space of family during festivals (Chang, 2016). The interaction in a family group without the participation of older family members seems active. Still, it is a false impression that interactions without elders, who are important family members, are not as meaningful as traditional family interaction.

\section{CONCLUSION}

This paper analyzed Chinese WeChat user behavior from interpretivism and came up with the following ideas. Chinese WeChat user behavior shows the following features: the expression of personality, the connection between individuals, group establishment by individuals, and the connection between individual and group. First, WeChat enables users to become unique individuals and show their personalities in certain social circles. Second, users can use WeChat as a primary social connection tool to communicate with others and establish various WeChat groups according to what is shared among friends. The connection between individuals and groups has become stronger with the launch of WeChat. In general, WeChat user behavioral features can be summarized as individual-oriented social connections. To some degree, the WeChat world can substitute the physical world, and some people can choose to live in it. However, the individual-oriented social connection may cause such problems as false impressions of individuals and false beliefs of interactions.

The WeChat user behavior investigated in this paper could be summarized as individual-oriented interactive social connections. Such a social connection has two essential features. First, it is individualoriented; second, it connects individuals and between "individual and group." Such new social connections will change traditional Chinese social connections into a new social order and impose challenges on the social system and the making of laws. As for the marketing of enterprises, it will bring new opportunities as well as problems.

Due to the restriction on the article's length, this paper could not explore other Chinese WeChat user behavior aspects. What are the behavioral features of WeChat users outside of China? What are the differences in behavior between Chinese and non-Chinese WeChat users? Can such behavior reveal the ideas of interpretivism? How to make an in-depth analysis of other Chinese WeChat user behavior from the perspective of interpretivism? All these issues need to be further discussed in future studies.

\section{REFERENCES}

Chang, F. (2016). Study on the Operational Model of WeChat Gift Money for Chinese Spring Festival in Chinese Familial Bonds. Social Sciences in Nanjing, (11), 103.

Chao, Y.L. (2018). Mechanism and Response: In-depth Analysis of Public Events on WeChat. Journal of Intelligence, 37(3), 131-132.

Chiang, C.K. (2014). Addiction to WeChat: Social Illusion and Self Loss. Social Sciences in Nanjing, (11), 100 . 
Chiang, C.M. (2017). A Philosophical Analysis of the WeChat Culture. Journal of Socialist Theory Guide, (7), 41.

Chu, H.Y. (2007). Bidirectional Analysis of Educational Organization Research MethodologyStructural Functionalism and Interpretivism in Educational Organization Research. Theory and Practice of Education, 27(1), 15.

Hsu, D.D. (2018). Current Development of WeChat Business People in China and the Analysis of Problems, Brand Research, (4), 94.

Inagaki, Y. (2013). Interpretation of management. Japan: Hakuto publishing.

Iydnews. (2014). Netizens and Their Fingertips-2014 Analysis on mobile network users' behaviors Retrieved February 8. 2018, from http://www.iydnews.com/2323.html

Lee, L. (2015). Foresight and Dialogue - An Introductory Analysis of the Opinions on WeChat from the Perspective of Philosophical Hermeneutics. Journal of Beijing Institute of Technology (Social Sciences Edition), 17(5), 156-161.

Lee, S.H., \& Yang, L. (2015). Study on the Factors That Influence Consumers' Decision on Purchase in the C2C WeChat Shopping. Consumption Economy, 31(5), 56.

Lee, Y. (2014). Analysis of the Change to the Interpersonal Communication behind the WeChat Communication Mechanism. Jianghan Tribune, (5), 141.

Liang, S.S. (2008). Something about a Cyber Catchword - "Sharing." Journal of Xinjiang Education Institute, (6), 97-98.

Liu, T.Y., \& Hsu, C. (2014). The Spreading, Sharing and Meaning Construction of WeChat: A Literature Review. Chongqing Academy of Social Sciences, (1), 97-101.

Ma, H.T. (2018). WeChat has over 1 billion monthly active users across the world. Retrieved from http://tech.163.com/18/0305/09/DC4F9BDR00097U7R.html

Mao, Y.P., \& Chi, F. (2017). Influence of the Information Delivery of WeChat Business People on Consumers' Intention of Acceptance. Economy and Management, 31(6), 67.

Peng, L. (2017). Social Meaning in WeChat Gift Money. Journal of Shanxi University (Philosophy and Social Sciences), 40(4), 61.

Sun, T.Y. (2014). Those who sell goods on WeChat Moment are not WeChat business people and will be definitely reshuffled. Retrieved from http://www.ebrun.com

Sun, W. (2015). WeChat: The "Living Existence" of the Chinese People. Academic Monthly, 47(12), 518.

Tencent. (2015). Retrieved August 2018, from http://tech.qq.com/original/tmtdecode/t846.html

TechWeb. (2018). Retrieved August 2018, from http://www.techweb.com.cn/internet/2018-0222/2639303.shtml

Wang, H.B. (2016). Sociological Analysis of Consumption Alienation on WeChat. Jiangxi Social Sciences, 36(11), 219.

Wang, H., \& Chu, Y. (2014). Discussion on WeChat Functions from an Interpersonal Perspective. Journal of Modern Information, 34(2), 85.

Wang, H., \& Kuan, C.W. (2016). Study on the "Sharing" on WeChat Moment. Journal of Chongqing University of Posts and Telecommunications (Social Science Edition), 28(3), 76-77.

Wang, L.H., \& Shih, Y.C. (2018). WeChat Business-based Analysis of Customer Behaviours and Interests. Journal of Jilin Institute of Chemical Technology, 35(2), 84-92.

Wang, L.N., \& Lan, C. (2017). Self-expression of Young People on WeChat Moment - A Study Based on Virtual Ethnography. Jinan Journal (Philosophy \& Social Science Edition), 39(12), 115-125.

Wang, Y.C. (2014). WeChat Opinion Field: Formation, Features and Opinion Efficacy. Journal of Intelligence, 33(7), 149.

Yin, C.F., \& Hu, W.C. (2018). Ethical Function and Potential Dangers of WeChat Moment from the Ritual View of Communication. Morality and Civilization. Morality and Civilization, (2), 126-132. 